\title{
ACHME IT SCHACHBRETT ODER HALT DICH FEST AN MEINEN OHREN
}

1 chim Schatten (Krefeld 1963), den Leserlnnen bereits von der Erzählung "Holz" im mAGAzin3 bekannt, treibt es liebend gern dahin, wo Anstandsbürgern die Klappe runterfällt, sie sich Mund, Ohren und Augen zuhalten, aber doch zwischen den Fingern durchlugen. Konsequent und im Grunde zutiefst moralisch, lässt er keine halben Töne zu, weder als Musiker - wie in seiner Punk-Operette "Im Land des Hechelns"1 oder den Performances mit seinem PunkDuo "Harald-Hitler-Band"2 - noch als Maler, noch als Dichter, und auch nicht als Schauspieler: im Moment ist er bei den Dreharbeiten zu einem Horror-Kurzfilm mit Teletubbies, in dem er den Papst spielt. Im Allgemeinen stochert er, manchmal pathetisch, manchmal lapidar, nach Verfaultem und Gelogenem, macht dem politisch Korrekten den Garaus und befördert dabei Ängste und Agressionen zu $\mathrm{m}$ Tage, die sich augenblicklich selbst entlarven. Die beabsichtigten Folgen sind einerseits Entrüstung der Scheinheiligen und Humorlosen und andererseits Beifall und befreiendes Lachen des Publikums. Welches Publikum? Schatten brilliert vor allem beim Rezitat, dem Ur-
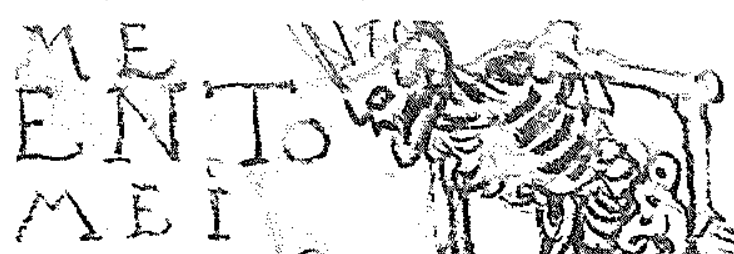

Su propio impulso natural le lleva a este autor bajorre nano, al que los/las lectores/as del mAGAzin número 3 y a conocen por su cuento "Madera", a lugares en donde a los ciudadanos bienpensantes se les caen los palos del sombrajo, donde se tapan oidos, boca y ojos pero no pueden dejar de espiar por entre los dedos. Consecuente consigo mismo y profundamente moralista en el fondo, no admite medias tintas, ni como músico - como en su opereta punk "En el pais del sol jodiente" o sus happenings con su duo punk "Harald-Hitler-Band" - ni como pintor, ni como poeta, ni tampoco como actor: actualmente está rodando un corto de horror de Teletubbies donde hace de Papa Juan Pablo II. En un tono entre elegíaco y lapidario, suele remover los despojos y mentiras humanas, castigar lo políticamente correcto, para poner en evidencia todos esos miedos y agresiones bien guardadas. En consecuencia bien premeditada, por un lado, se escuecen los hipócritas y mentecatos, y por el otro, el público aplaude y se rie con ganas. ¿Que público? Es sobre todo en el recital, el marco verdadero de la poesía donde Schatten desplega sus talentos: su vozarrón retumba por encima de los mares de cerveza

a Muerte coronada sobre un caballo flaco. Alberto Durero element der Dichtung: elegisch hallt seine Stimme über die Biermeere in der Szene-Kneipe, und Zwischenrufer kriegen direkt eine Breitseite Paroli. Denn Schatten hat nicht nur Spürsinn für Blend-Ästhetik und Scheinmoral, sondern auch jede Menge Witz. Bei inm kein Problem, denn Leben und Kunst sind für ihn ein und dasselbe: Freiheit, Spass, Klarheit und Wahrheit.

Kommentar und Übersetzung von Christoph Ehlers de los locales de la movida, y los comentaristas inoportunos reciben una prueba de sus golpes verbales. Porque Schatten no sólo tiene olfato para la estética hueca y la doble moral, sino también humor a espuertas. Para él eso no es ningun problema, pues para él vida y arte es lo mismo: libertad, diversión, claridad y verdad.

Comentario y Traducción de Christoph Ehlers 
LIEBE 3

liebe ist ein böses wort

es treibt zur lüge

es treibt zum mord

mord ist ein schönes wort

denn es ist ehrlich

aber es auszusprechen

je nach kontext

gefährlich

soldaten sind mörder

darf man jetzt nicht mehr sagen

ich sage mörder sind soldaten

ob die mörder mich jetzt verklagen?

die schere im kopf

die das wort abschneidet

das ist demokratie

um die man uns beneidet währenddessen wird Tucholsky

im geschichtsbuch bemitleidet

er hat was kluges gesagt

und das war dumm

deswegen drehen wir den alten

per gerichtsbeschluss

im grabe rum

mit tut der schädel weh

der körper

die beine

bis runter

in den grossen zeh

......

BRD

BRD

\section{AMOR}

amor es una palabra malvada

incita a la mentira

incita a la puñalada

asesinato es una palabra bonita

porque es sentida

pero al pronunciarla

puedes, según el contexto,

cagarla.

los soldados son asesinos

ahora esta prohibido afirmar

yo digo: los asesinos son soldados

¿y si ahora los asesinos me quieren

demandar?

la tjera en la mente

que corta las palabras

eso es la democracia

en la que nadie nos supera

mientras, en los libros de historia

de Tucholsky se conmiseran

dijo algo inteligente

lo cual fue fatal

por eso removeremos

al viejo en la tumba

por orden judicial

me duelen las entrañas

la cabeza

las piernas

hasta llegar abajo

a la punta de tamaña

República de Alemania

República de Alemania 


\section{WÜRDE! VERSTAND!}

Es gibt ein wort

und das heisst würde

und das ist eines menschen bürde

und diese bürde muss er tragen

und nicht da sitzen

und von sich sagen

"zuviel gewürge mit der würde

scheisse auf mein ich-bild"

ich bin deutsch

der verstand sagt leise

"tilt"

der finger gehört nicht

ins eigene poloch

er gehört mahnend erhoben

denn schaut euch nur um

ringsum wird gelogen

es gibt ein wort

und das heisst verstand

das ist es

woran alles krankt

verstand kommt von verständigung

alles rennt mit'm handy rum

kommunikation

der pure hohn

versucht's doch mal mit sprechen

inr affen

ich drück euch die daumen

ihr könntet es schaffen

verstand in unserem Land dient doch nur der bändigung

von worten

zwecks behinderung

der verständigung

damit man's nicht versteht

die zeit aber doch

irgendwie vergeht.]

\section{¡DIGNIDAD! ¡IENTENDIMIENTO!}

Hay una palabra

que es 'dignidad'

que es la carga de la humanidad

y la carga hay que soportarla

y no mirar la luna

diciendo con voz amarga

"demasiada dificultad con la dignidad

mi ego me la suda"

soy alemán

y la razón me susurra

"averia"

el dedo no hay que meterlo

donde más gusto daría

hay que levantarlo advirtiendo

pues echad un vistazo

cómo se está mintiendo.

hay una palabra

que es 'entendimiento'

eso es

lo que el mundo está padeciendo

entendimiento viene de entenderse

todo quisquis con su móvil deja verse

comunicación

una pura contradicción

¿porqué no intentáis

hablar, so juláis

os deseo suerte

a lo mejor lo lográis.

en nuestro país, el entendimiento tiene la función de domesticación de las palabras, poner un impedimento a la comunicación

para que nada se capte pero el tiempo igualmente pase.
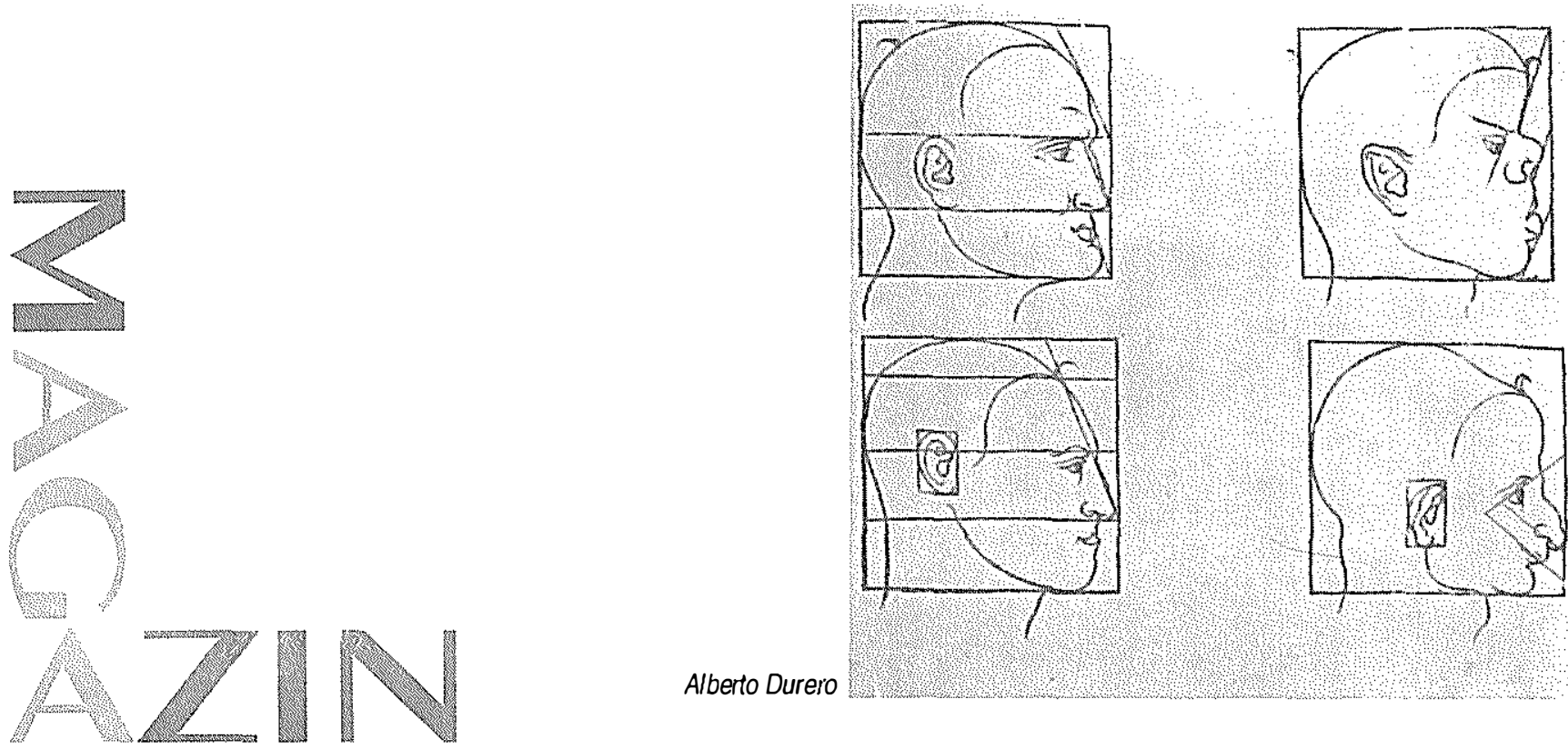


\section{KUNST \\ STINKEN}

kunst.........................stinken

kunst.........................stinken

kunst..........................stinken

kunst..........................stinken

und

in belanglosigkeit versinken

warm weich wohlig und belan-

glosig-

keit und nicht heiter

ääähh, weiter

kunst. stinken

kunst stinken

kunst. stinken

kunst. stinken

und

vermarkten und verkaufen

dumm reden und dumm saufen

belanglos heiter

hab's zu was gebracht ääähh, weiter

kunst. stinken

kunst stinken

kunst stinken

kunst stinken

\section{ARTE}

arte

arte

arte

arte

$y$

de aburrimiento bostezar

calentito suavito e insignificativo y nada divertido

eehh, sigo

$\begin{array}{ll}\text { arte } & \text { apestar } \\ \text { arte } & \text { apestar } \\ \text { arte } & \text { apestar } \\ \text { arte } & \text { apestar } \\ y & \end{array}$

comerciar y vender

decir bobadas y no saber beber nada subversivo

la fama he conseguido eehhh, sigo

$\begin{array}{ll}\text { arte } & \text { apestar } \\ \text { arte } & \text { apestar } \\ \text { arte } & \text { apestar } \\ \text { arte } & \text { apestar }\end{array}$

ONANIE, HI, HI

Ich bin entspannt

ganz entspannt

im hier und jetzt

ich fröne einer leidenschaft

die hat sich festgesetzt

im ich

im ich

da brennt ein kleines feuer

manchmal brüllt ein ungeheuer

leichtes unwohlsein

biermelancholie

griff zum pinsel

armschwung

besser jetzt als nie

ich rede nicht vom malen

ich red von onanie

hi, hi

im ich

da lodert eine lunte

macht mich zum macho

mal zur tunte

heisst wildes tun

und hände die nie ruhn

schlenker, schlenker

schüttela und schüttelie

ich rede nicht vom malen

ich red von onanie

hi, hi

im ich da wildern tiere

fressen, brüllen

kacken, jagen

ich will dem aufruhr

nicht entsagen

ich find das gut

ich hab das gern

denn brüllt ein tier

entsteht ein stern

im ich
PAJA, JA, JA

Estoy relajado

completamente relajado

en el aquí y el ahora

cultivo una aficción

cautivadora

dentro de mí.

dentro de mi

arde una débil llama

a veces la bestia brama

leve malestar

cerveza, resaca

cojo la brocha

alzo el brazo

mejor ahora que nunca

no hablo de pintura

hablo de la paja

ja, ja.

dentro de mi

una mecha crepita

unas veces soy macho

$y$ otras marica

- sea, una salvajada

manos que nunca se paran

mecer; mecer

meneó, meneí, me relaja

no hablo de pintura

hablo de la paja

ja, ja

dentro de mi los animales campan comer; cagar

gritar, cazar

a este tumulto

no pienso renunciar

me da gustito

me da placer

porque cuando la bestia ruge

una estrella siento nacer

dentro de mí.

ampan
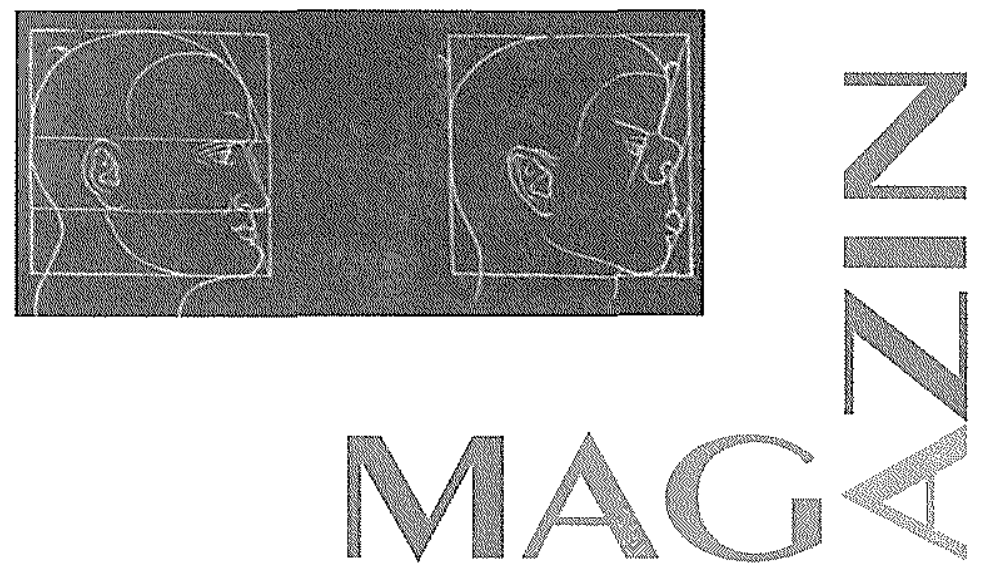
MEIN KLEINES SADOMASOCHISTISCHES SCHLAGERSTUDIO IN DEM AUCH MIT ESSEN GESAUT WIRD

Peter Alexander

ist mein Gefangener

in meinem Zimmer

für immer

und dann

Peter der Große

Ich übergieß inn mit Soße

Die goldene Kehle aus Prag

Ich weiss nicht was den Frauen

an inm lag

Ist mein Gefangener

In meinem Zimmer

Für immer

Und dann

Karel Gott

auf den Schädel Kompott

Roberto Blanco

Er kann nicht singen

Das ist sein Manko

ist mein Gefangener

in meinem Zimmer

für immer

und dann

welch Schicksalsstreich

eine Wanne voll Blutwurst

setz dich rein, jetzt gleich.

Katja Epstein

ihr Traum: verdreckt sein

das kann sie haben

ist meine Gefangene

in meinem Zimmer

für immer

und dann

Katja Epstein

du wirst bedeckt sein

von vergornem Schleim.

MI PEQUEÑO ESTUDIO SADO-
MASO DE GRABACIÓN DE
CANCIÓN HORTERA ALEMANA
EN EL QUE TAMBIÉN SE
HACEN GUARRADAS CON LA
\[ \text { COMIDA } \]
[El traductor está a punto de ren-
dirse]
A Camilo Sesto
lo he hecho prisionero
en mi cuarto
nunca lo entrego
y luego
a Camilo Sesto
lo unto con pesto
La voz de oro de Andalucia
no sé cómo les gustaba a las tias
Es mi prisionero
en mi cuarto
nunca lo entrego
y luego
a Joselito
le vuelco gazpachito.
[El traductor se rinde. El Traductor]

Conny Francis

oft kann sie's

ich meine das Singen

doch reden wir

von anderen Dingen

ist meine Gefangene

in meinem Zimmer

für immer

und dann

Conny Francis

kriegt Kotzklümpchen

mit Biss.

Jetzt denkt inr von mir ich könnt sie nicht leiden den Erfolg würd ich ihnen neiden

Ja sogar denn Genuss von

Singels und Langspielplatten vermeiden.

Das lass ich so nicht stehen

Mich hat die Phantasie erregt am Arsch

der sich schunkelnd bewegt

da bin ich einfach durchgebrannt durchgeknallt und abgehoben ich war ne ganz e Weile oben und als ich weider landete in einem Meer aus Schlagerblau den Himmel rosa

im Herzen flau

da begann ich zu verstehn

willst du mit mir gehn

Licht und Schatten verdrehn

Amarillo, Lodz und Moskauer

Nächte

Ich will das alles

Nicht mehr das Schlechte

Zitat:

Schön ist es auf der Welt zu sein

Sagt die Biene zu dem Stachelschwein

Du und ich wir stimmen ein

Schön ist es auf der Welt zu sein

Zitatende

\section{¿El traductor se rinde?}

Se convoca un CONCURSO entre los lectores del mAGAzin para echarle una mano.

O sea: estrofas con intérpretes de pop o canción melódica española objeto de guarradas con comida. Premio: publicación en el mAGAzin y CD sorpresa.

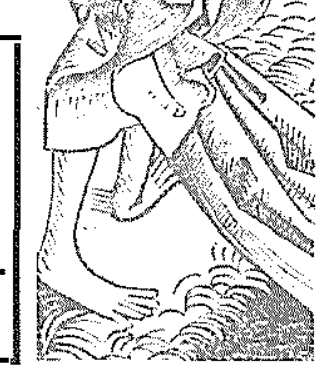

Wie recht sie haben diese Menschen

Ich wusste das wirklich nicht

Deutscher Schlager

du bringst uns Licht.

Frei nach Franz Lèhars "Im Land des Lächelns"

Der Name hats natürlich in sich: ein Konzert im Avantgarde-Kulturzentrum von Lyon (Frankreich) führte zum politischen Eklat, in dessen Verlauf der Landespräsident sich im Femsehen entschieden gegen solche "Neo-Nazis" aussprach. Der Witz bei der Sache: der Herr war von der Partei von Le Pen.

Beitrag zum Urtell des Bundesverfassungsgericht, das 1997 den Satz "Soldaten sind Mörder" verbot. Kurt Tucholsky hatte 1930 dasselbe gesagt.
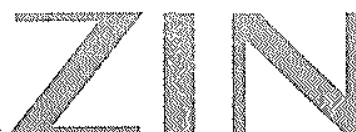